\title{
Detecting the Depth of a Subsurface Brine Layer in Lop Nur Lake Basin Using Polarimetric L-Band SAR
}

\author{
Chang-An Liu, ${ }^{1,2}$ Huaze Gong, ${ }^{1}$ Yun Shao, ${ }^{1}$ and Bingyan $\mathrm{Li}^{3}$ \\ ${ }^{1}$ Institute of Remote Sensing and Digital Earth, Chinese Academy of Sciences, Datun Road, Beijing 100101, China \\ ${ }^{2}$ University of Chinese Academy of Science, Beijing 100049, China \\ ${ }^{3}$ China University of Geosciences Beijing 100083, China
}

Correspondence should be addressed to Huaze Gong; gonghz@radi.ac.cn

Received 28 October 2014; Revised 15 January 2015; Accepted 5 February 2015

Academic Editor: Yoshio Yamaguchi

Copyright (C) 2015 Chang-An Liu et al. This is an open access article distributed under the Creative Commons Attribution License, which permits unrestricted use, distribution, and reproduction in any medium, provided the original work is properly cited.

\begin{abstract}
Lop Nur once was a huge lake located in northwestern China. At present, there is no surface water in Lop Nur Lake basin and on SAR images it looks like an "Ear." The objective of this paper is to retrieve the depth of subsurface brine layer in Lop Nur by copolarized phase difference of surface scattering. Based on field investigation and analysis of sample properties, a two-layer scattering structure was proposed with detailed explanations of scattering mechanisms. The relationship between copolarized phase difference and the brine layer depth in the region of Lop Nur were studied. The copolarized phase difference of surface scattering was extracted by model-based polarimetric decomposition method. A good linear correlation between measured subsurface brine layer depth and copolarized phase difference with R2 reaching 0.82 was found. Furthermore, the subsurface brine layer depth of the entire lake area was analyzed. According to the retrieved maps, some interesting phenomena were found, and several hypotheses about the past water withdrawal process and the environmental evolution had been proposed to theoretically explain these phenomena. Based on the penetration capability of SAR the reconstruction of historical evolution process of Lop Nur will be an interesting topic for future research.
\end{abstract}

\section{Introduction}

Lop Nur was once an extensive lake located in the Xinjiang Uygur Autonomous Region in the eastern Tarim Basin, in northwestern China. Lop Nur is located in a typical arid region, which is highly sensitive to climate change, and its history of environmental changes is significant for understanding historic global climate change [1-3]. The Lop Nur basin was an important section of the ancient "Silk Road," famous as the prosperous communication channel between Eastern and Western cultures. However, Lop Nur has completely dried up during the 20th century, leaving earshaped concentric strips (interchanging bright-grey appearance) visible in remote sensing images (Figure 1) [4-6]. Many assumptions have been made about its formation, but they remain to be proven by scientific evidence, and therefore its formation has remained a mystery [7]. It has been called the "Drought Pole" and the "Sea of Death" because of its extremely dry conditions and poor accessibility [6]. The lake area may expand and shrink several times because of the periodic arrival of moist airflow or flooding. It serves as a region of salt and water accumulation in the Tarim Basin and is therefore rich in mineral salts with many salts at the surface and very low moisture content. With the penetration ability of synthetic aperture radar (SAR) signals and the arid environment of Lop Nur, it is believed that SAR can detect subsurface targets and reflect the information of the thickness of the dry soil layer [8].

One of the significant advantages of SAR is penetrating dry soil. In 1981, space shuttle Columbia installed an Lband $\mathrm{HH}$ polarization imaging radar system SIR-A and obtained many images. Scientists have made many valuable applications of the results. Most notably, McCauley of the United States Geological Survey found ancient river and human remains in the eastern Sahara desert under sand cover using SIR-A image analysis, which caused a sensation in the remote sensing and meteorological communities [9]. Blom found igneous dikes buried under up to $2 \mathrm{~m}$ of alluvium in 


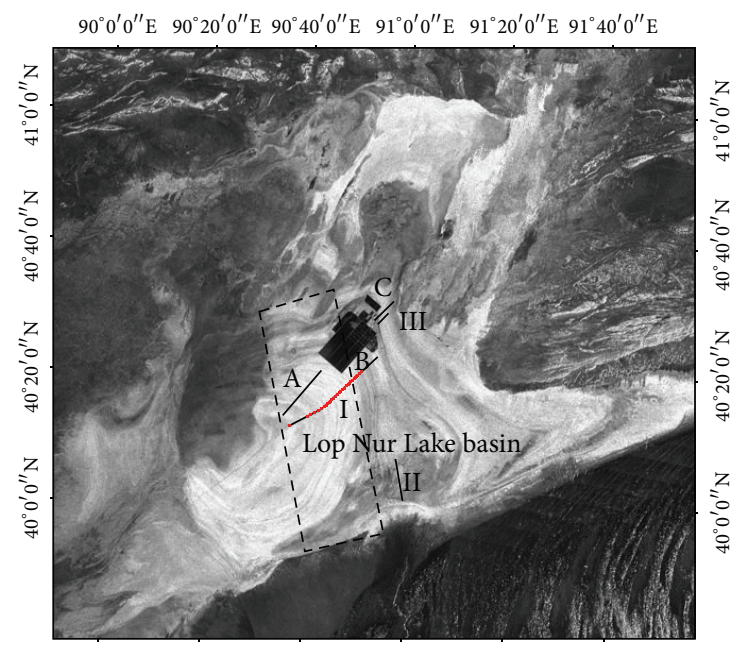

$90^{\circ} 0^{\prime} 0^{\prime \prime} \mathrm{E} \quad 90^{\circ} 20^{\prime} 0^{\prime \prime} \mathrm{E} \quad 90^{\circ} 40^{\prime} 0^{\prime \prime} \mathrm{E} \quad 91^{\circ} 0^{\prime} 0^{\prime \prime} \mathrm{E} \quad 91^{\circ} 20^{\prime} 0^{\prime \prime} \mathrm{E} \quad 91^{\circ} 40^{\prime} 0^{\prime \prime} \mathrm{E}$

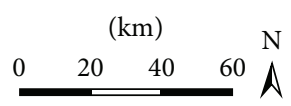

FIGURE 1: Field investigation routes and sampling site locations. A, B, and C are field routes in 2006, and I, II, and III are field routes in 2008. The dashed rectangle is the coverage of full-polarimetric SAR data used in the last part of this paper and the red dots are positions of sampling sites of 2013. There is a large salt pond in the middle of the image as a black square. ALOS-PALSAR image ( $\mathrm{HH}$ polarization, ScanSAR mode) obtained on January 15, 2011, were used as base map.

the Mojave Desert of California detected by the SEASAT Lband (23.5-cm wavelength) SAR [10]. These findings suggest that subsurface features with potential tectonic or geomorphic significance may be revealed in other orbital radar images in semiarid terrains. Schaber et al. further studied the effects of physical factors that affect penetration and attenuation $[11,12]$ and found that the estimated penetration depth of L-band radar is approximately $1.5 \mathrm{~m}$ through sandy sediment in the southern desert of Egypt [13]. In addition, there are many scientists using SIR-B and SIR-C to study subsurface geological structures and radar penetration depth in desert areas [14-17].

In radar remote sensing, copolarized phase difference has a lot of physical meaning and special significance. Lasne et al. found that the copolarized phase difference has a good correlation with the depth of the dry sand layer [18]. This phase signature may be used as a new tool to map subsurface moisture in arid regions. In their study, a phase difference of $23^{\circ}$ between the horizontal $(\mathrm{HH})$ and vertical (VV) channels was clearly observed. It allows the detection of the wet paleosoil down to a greater depth $(5.2 \mathrm{~m})$ than when only considering $\mathrm{HH}$ and $\mathrm{HV}$ amplitude signals $(3.5 \mathrm{~m})$. They performed several experiments and published many articles to validate their theory [19-23]. Lop Nur also has a two-layer soil structure area and therefore, based on the theory of Lasne et al., we will study the copolarized phase difference in the Lop Nur Lake Basin.

The theory of Lasne et al. is based on the field created by a wet paleosoil layer, which is covered by a dry sand layer. The structure of their research objective is relatively simple, while the structure and chemical composition of the soil layer in the Lop Nur region is more complex, with a rough rock shell on the top surface (Figure 2), and an aqueous saline soil layer in the subsurface. It therefore has complex scattering mechanisms that in this area not only include pure surface scattering, but also subsurface scattering with a complex signal propagation mechanism. To study and verify the applicability of the phase signature based inversion methods of soil thickness in the Lop Nur region, we applied the ALOS L-band full polarization data and the model-based polarization decomposition method to extract copolarized phase difference of the surface scattering. Based on the theory of Lasne et al. [18], we established an empirical relationship between the underground aquifer layer depth and the copolarized phase difference of the surface scattering. The objective of this study was to model and validate the capabilities of the L-band ALOS SAR to penetrate saline soil to detect the subsurface aquifer and to invert the underground aquifer layer depth and use the depth inversion map to study the distribution of the subsurface brine layer in the Lop Nur Lake region.

The study of the underground aquifer depth in the Lop Nur region is of profound environmental and climatic significance. It can reflect the distribution of the underground brine layer in the basin area, revealing subsurface structures below the rock shell, and contribute to the analysis of the cause of the large ear feature in the Lop Nur Lake. Furthermore, this work can provide reference information on past climate history. In addition, the proposed methodology can also be used for detecting underground aquifers in arid regions and the assessment of the stages of farmland soil drought.

First, the test site and field investigations are described. The principles and methods are introduced in the next section. The experimental inversion results of the subsurface brine layer depth of a line perpendicular to the stripes and the entire area are presented and discussed in section three. Finally, conclusions and future topics are presented at the end of this paper.

\section{Materials and Methods}

\subsection{Test Site and Field Investigations}

2.1.1. Test Site Description and Image Data. Lop Nur is located in the eastern Tarim Basin in the Xinjiang Uygur Autonomous Region, northwest China. Historically, the major rivers flowing into Lop Nur included the Tarim, Kongqi, and Qarqan rivers carrying large amounts of mineral salts. Because of its special geographical position in the Tarim Basin, mineral salts accumulated producing high salt concentrations in this area, in particular, rich potassium deposits. The basin is located at approximately $39.5^{\circ}$ to $41.5^{\circ} \mathrm{N}$ and $88^{\circ}$ to $92^{\circ} \mathrm{E}$, and its lowest altitude is approximately $785 \mathrm{~m}$ $[1,2]$. Because Lop Nur is located far from any ocean and the northeasterly winds prevail throughout the year, it is difficult for moist marine air masses to reach the area; thus, the climate is extremely arid. It is the most arid region of Eurasia, with less than $20 \mathrm{~mm}$ of annual precipitation and over $3000 \mathrm{~mm}$ of 

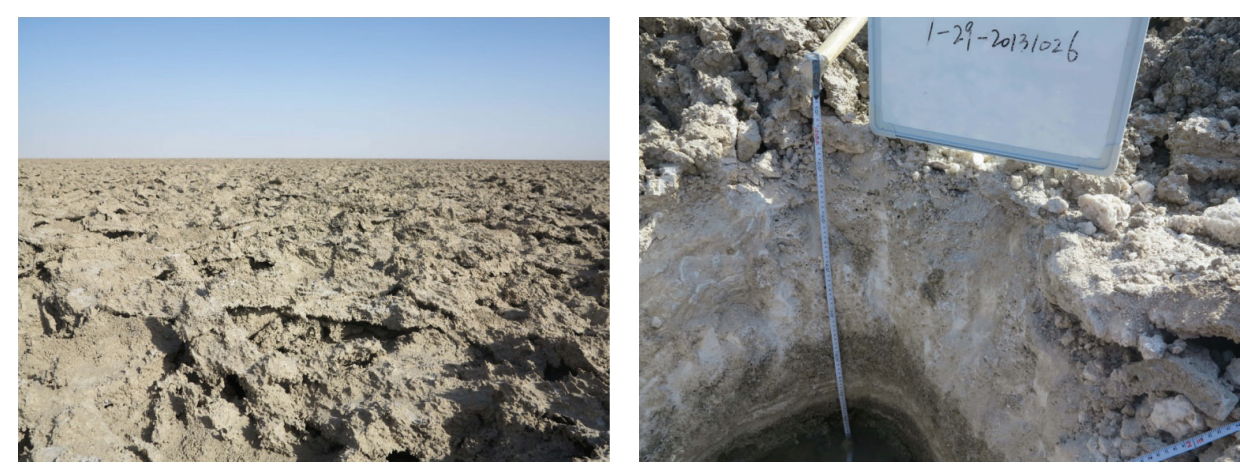

FIGURE 2: Photos of surface conditions and field sampling.

evaporation. The former lake bed displays features of extreme salinification and severe wind erosion, and a large number of rimosus salt crusts are found in the lake basin, resulting in an extremely coarse surface and fairly complex scattering mechanisms that developed during soil formation [8].

Optical and radar images of the Lop Nur Lake area show alternating light and dark textures, where the ring-shaped contour texture resembles a large ear, as shown in Figure 1. Lop Nur is a typical extreme arid region of western China and the world with its changes and history of drying recording the changes in the environment. Studies have shown that the Lop Nur ear feature is a true record of the demise of the lake, with implications for climate change from wet to dry. Remote sensing technology facilitates the spatial analysis of the distribution of the Lop Nur Lake sediments, which can help us analyze global climate change in arid regions.

Figure 1 shows the investigated routes and the distribution of the sampling points, and Figure 2 shows the surface condition and outdoor soil sample collection. $\mathrm{HH}$ polarization and ScanSAR mode ALOS-PALSAR data obtained on January 15, 2011, were used as the base map in Figure 1.

Because the radar signals at the L-band have relatively high penetration, this study uses mainly the ALOS-PALSAR remote sensing data to analyze the scattering characteristics of the Lop Nur Lake basin and to perform a phase signature study based on the Freeman target decomposition method. The L-band ALOS-PALSAR imagery for the Lop Nur area is the full polarimetric mode obtained on May 6, 2009, and the off-nadir angle is $23.1^{\circ}$. Images were reprojected onto the UTM/WGS84 coordinate system after basic radiation and geometric correction and processed with PolSARprov4.0 and ENVI 5.0 software.

2.1.2. Field Investigation and Sample Collection. To obtain detailed information on the composition and structure of the surface and subsurface features in the study area, the research group performed six scientific field investigations in Lop Nur, beginning in 2006. The field investigations and measurements define the existing knowledge and research results from Lop Nur and provide powerful data in support of the subsequent quantitative analysis of the scattering mechanisms.

We visited the ruins of the Loulan Kingdom and the Lop Nur Lake basin, where lacustrine deposits were sampled along a $41 \mathrm{~km}$ profile at intervals of $2 \mathrm{~km}$ to the northeast of the Lop Nur Lake, as shown in Figure 1. Lacustrine samples from the surface and subsurface were collected at every sampling site. Twelve salt crystal and brine samples were also collected from certain sampling sites. The second field investigation was conducted in November 2008, when GPR (Ground Penetrating Radar) was first used to collect Lop Nur subsurface structural information. In November 2008 field investigation, the GPR detected a boundary between the dry upper layer and the wet lower layer at depth of about $50-55 \mathrm{~cm}$, ranging from the centre to the edge. The measurements made by GPR have the same trend with L-band SAR. Another three field trips were completed in December 2008, April 2010, and November 2010 to determine the northern and western parts of the shoreline and to verify the existence of the shoreline of the East Lop Nur Lake, which has been buried by the lacustrine deposits of the West Lop Nur Lake.

The 2013 field experiments spanned from October 14 to November 3, for a period of 21 days, and this paper is based on this field investigation. The main work included radar remote sensing field sampling, surveying and sampling the OSL sample area, spectral measurement, and sampling. Among them, the radar remote sensing field sampling and spectral measurement expedition route was the same as the route in 2008. Field samples were collected from 43 locations with a total of 622 samples, including 224 large and small boxes for measuring ion content and moisture content, 114 boxes for laboratory measurement of dielectric properties, and 60 optical luminescence light specimens. Based on their sedimentary characteristics, six lacustrine deposit samples were collected for each sampling site from the surface to the base of each sampling pit at different depths and numbered as samples one through six. The depth of the pits ranged from $50 \mathrm{~cm}$ to $120 \mathrm{~cm}$. The samples were kept fresh in sampling boxes and transported to the laboratory for analysis, including moisture testing, ion content (e.g., $\mathrm{Na}^{+}, \mathrm{Ca}^{2+}, \mathrm{K}^{+}$, $\mathrm{Cl}^{-}$, and $\left.\mathrm{SO}_{4}{ }^{2-}\right)$, particle size, $\mathrm{pH}$, and the real $\left(\varepsilon^{\prime}\right)$ and imaginary $\left(\varepsilon^{\prime \prime}\right)$ parts of the dielectric constant.

\subsection{Principles and Methods}

2.2.1. Scattering Mechanisms and Phase Signature. Because of the extremely dry rough surface morphology of the Lop Nur 


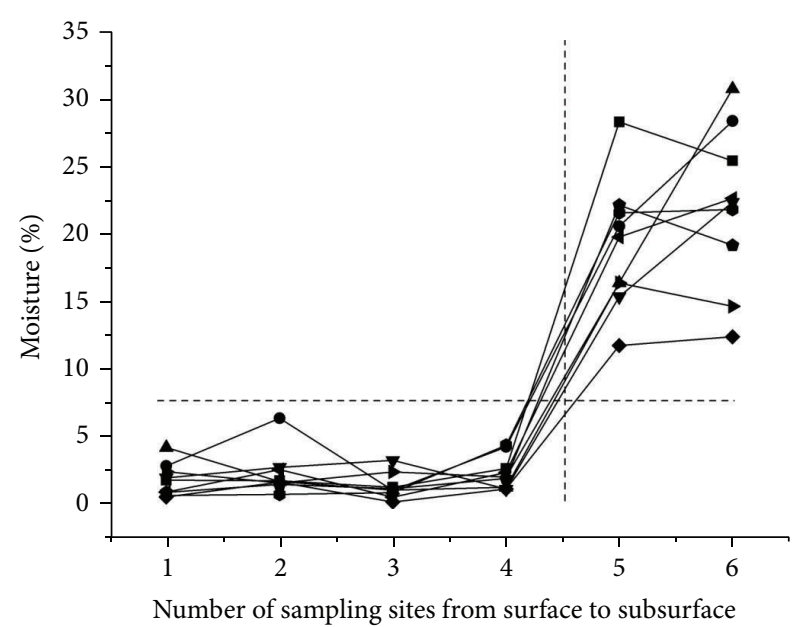

FIGURE 3: Moisture variation from surface to base of the lacustrine deposits at selected sampling sites. It can be seen that the moisture increased abruptly rather than gradually from the fourth sample (average depth of $40 \mathrm{~cm}$ ) to the fifth sample (average depth of $50 \mathrm{~cm}$ ) counting from surface to base in each sampling pit. The fourth and fifth samples were from different depths at different sites. The average moisture of the first four samples was approximately $2 \%$, but the moisture of the fifth sample increased to $10 \%$ at least. The dash line in the figure stands for the significant difference.

area and the unique ability of SAR to penetrate in the arid region, the scattering mechanism in this area includes pure surface scattering and complex signal propagation mechanisms in subsurface structure. Based on the Lop Nur radar image features combined with field and laboratory measurement data, we conclude that there is a special subsurface layer in the Lop Nur Lake area with different dielectric properties from the other layers (wet and dry change interface). At present, the bed of the Lop Nur Lake is extremely flat and uniform, with endless dry salt crust in all directions. The upper layer of the salt crust is extremely dry with no water content, resulting in a very low complex dielectric constant (the dielectric constants of upper layer is very low, about 3-0.2 j for C band and 3.5-1 j for L band). However, with further digging into the lacustrine deposits, a moist layer was found beneath the upper dry layer on all sampling sites. Furthermore, at some sampling sites, brine was clearly visible and even gushed out. In general, brine is visible at depths of $50-60 \mathrm{~cm}$. Figure 3 shows that the moisture increased abruptly from the fourth (average depth of $40 \mathrm{~cm}$ ) to the fifth sample (average depth of $50 \mathrm{~cm}$ ), counting from the surface to the base in each sampling pit. The locations of the fourth and fifth samples are not fixed, because every sample site has its specific subsurface condition. The average moisture of the first four samples was approximately $2 \%$, but the moisture of the fifth sample increased to at least $10 \%$. From the center to the edge of the lake, the variation of moisture in the lacustrine deposits at the same layer position is not obvious [6].

For scattering mechanisms, the SAR signal can penetrate the rough surface to detect subsurface targets because the top layer has lower dielectric properties, which indicates that the attenuation effect on the signal is weak. Typically,



FIGURE 4: Two-layer structure and scattering mechanisms, where $\varepsilon$ stands for complex dielectric constants, $D$ is the thickness of layer $1, W$ represents Fourier transformation of surface correlation function, $S$ and $L$ are RMS height and correlation length, respectively, a is albedo, $\kappa e$ means extinction coefficient, and $\theta$ and $\theta^{\prime}$ accounts for incidence and transmission angles.

the various effects of signal propagation process cannot be considered one by one. Based on the actual situation, the structure can be simplified by highlighting the main factors to take advantage of a simple model or the combination of models for quantitative characterization. In Figure 4, the Lop Nur subsurface structure is simplified into a two-layer medium layer. For the bottom layer, the water content is close to saturation, the dielectric properties are significant, and the signals cannot continue to spread. Therefore, we only consider the second layer and the parts above it as the main factors.

When the signal arrives at the top interface, strong surface scattering will occur because of the rough microtopography. Then, the transmission effect will allow a partial signal to propagate sequentially into layer 1 , where absorption and volume scattering may attenuate the signal intensity. Here, to reduce the complexity of the modeling and to conduct validation combined with model-based polarimetric decomposition results, only the absorption effect is considered. After attenuation, the signal arrives at the bottom interface, where surface scattering occurs once more. Note that, in view of the simple sedimentary environment of Lop Nur, the roughness of the bottom interface is not severe. This assessment agrees with the GPR results, which show that the subsurface interface is much smoother. The signal will transmit continuously into the lower layer, but because of its notable dielectric properties, the imaginary part in particular, which accounts for the attenuation ability, has no strong backscattering intensity. In summary, only the surface scattering at the top and bottom interface and absorption attenuation are considered for the scattering mechanisms of Lop Nur [6]. Based on the measured parameters and the analysis described above, the two-layer structure was used in this study. The specific scattering mechanisms are shown in Figure 4. 


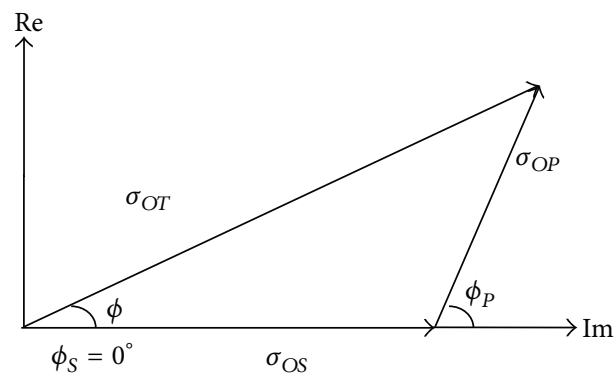

Figure 5: Total backscattered power $\sigma_{\text {OT }}$ is represented as the vectorial sum of the upper layer surface $\sigma_{\mathrm{OS}}$ and wet subsurface $\sigma_{\mathrm{OP}}$ contributions.

Based on the theory of Lasne et al., this two-level structure with a dry upper soil layer and a subsurface brine layer will have a copolarized phase difference in the PolSAR images. Next, we will briefly introduce this theory.

The total complex backscattered signal SAR is the coherent sum of the contributions of the top $S_{S}$ and bottom $S_{P}$ surfaces, which can be written as

$$
S_{T}=S_{S}+S_{P}
$$

with each term described by its amplitude $\sigma_{O}$ and phase $\phi$. Equation (1) can be represented as the sum of two vectors as shown in Figure 5 and we can set a phase origin so that the phase associated with the sand layer $\phi_{S}$ is zero. We can then express the $\mathrm{HH}$ and VV polarization as

$$
\begin{gathered}
\sigma_{\mathrm{OT}} \mathrm{HH} \angle \phi_{T} \mathrm{HH}=\sigma_{\mathrm{OS}} \mathrm{HH}+\sigma_{\mathrm{OP}} \mathrm{HH} \angle \phi_{P} \mathrm{HH}, \\
\sigma_{\mathrm{OT}} \mathrm{VV} \angle \phi_{T} V V=\sigma_{\mathrm{OS}} \mathrm{VV}+\sigma_{\mathrm{OP}} \mathrm{VV} \angle \phi_{P} V .
\end{gathered}
$$

With some approximation, we can assume that the phase of $\mathrm{HH}$ and $\mathrm{VV}$ signals backscattered by the bottom interface is the same:

$$
\phi_{P} \mathrm{HH}=\phi_{P} \mathrm{VV}=\phi_{P}
$$

The phase $\phi_{P}$ is only a function of the distance traveled by the incident wave through the sand layer of thickness $D$ :

$$
\phi_{P}=\Re\left[\frac{\left(D / \cos \theta^{\prime}\right)}{\left(\lambda / \sqrt{\varepsilon_{1}^{\prime}}\right)}\right] * 2 \pi
$$

with $\Re[A / B]$ as the remainder of $A$ divided by $B$.

Then, the phase of the total backscattered signal $\phi_{T}$ in Figure 5 can be expressed as

$$
\phi_{T}=\arctan \left(\frac{\sigma_{\mathrm{OP}} \sin \left(\phi_{P}\right)}{\sigma_{\mathrm{OS}}+\sigma_{\mathrm{OP}} \cos \left(\phi_{P}\right)}\right)
$$

and we can obtain the phase difference between $\mathrm{HH}$ and $\mathrm{VV}$ signals as

$$
\begin{aligned}
\phi_{\mathrm{HH}-\mathrm{VV}}= & \phi_{\mathrm{THH}}-\phi_{\mathrm{TVV}} \\
= & \arctan \left(\frac{\sigma_{\mathrm{OPHH}} \sin \left(\phi_{P}\right)}{\sigma_{\mathrm{OSHH}}+\sigma_{\mathrm{OPHH}} \cos \left(\phi_{P}\right)}\right) \\
& -\arctan \left(\frac{\sigma_{\mathrm{OPVV}} \sin \left(\phi_{P}\right)}{\sigma_{\mathrm{OSVV}}+\sigma_{\mathrm{OPVV}} \cos \left(\phi_{P}\right)}\right) .
\end{aligned}
$$

In [18] Lasne et al. found that the phase difference increases with respect to the thickness of the overlying sand. In the same article they used an analytical approach based on IEM, which was proposed by Fung [24, 25], that reproduced the phase difference between $\mathrm{HH}$ and VV signals as a function of the sand layer thickness. Using this analysis we discovered that our study area has similarities with theirs. In this paper, we will introduce this theory to the study of subsurface aquifers in the Lop Nur region.

The study area of Lasne et al. was a two-layered structure consisting of a layer of dry sand and a wet paleosoil layer, which is a relatively simple structure. In their study area, relatively weak surface scattering will occur at the surface of the first layer of dry sand. Then, following attenuation some of the signals will arrive at the second wet-paleosoil layer, and relatively strong surface scattering will occur at this layer there. As shown in Figure 4, when the SAR signals spread on to the surface in Lop Nur, the surface morphology is very rough at the interface of the first layer, and surface scattering will occur at the rough surface (including single and multiple scattering). Due to the low dielectric properties of layer 1 (very dry), part of the energy will spread into layer 1. In this process, we must take the attenuation effects into consideration. When the signals reach the interface between layers 2 and 1, there will be a surface-like scattering effect due to the differences of the dielectric properties between the two layers. The process and structure described above are suitable for the application of the theory of Lanse et al. However, because of the special structure and chemistry of the Lop Nur surface and subsurface soil, this area experiences surface, dihedral, and volume scattering. Therefore, we must use the model-based polarimetric decomposition method to calculate the copolarized phase difference corresponding to the surface scattering mechanism.

2.2.2. Model-Based Polarimetric Target Decomposition. There is a theoretical relationship between the copolarized phase difference of the surface scattering and the thickness of dry soil layer. In Lop Nur the two-layer scattering mechanism of the dry sediments is special and complex. This region has single and multiple scattering from the upper soil surface, surface scattering from the subsurface layer, and dihedral, volume, and other scattering mechanisms. To extract the phase difference of the contributions from surface scattering we applied the classical Freeman-Durden decomposition method. The Freeman-Durden decomposition is a technique for fitting a physically based, three-component scattering mechanism model to the polarimetric SAR observations, 
without using any ground truth measurements [26, 27]. It decomposes the targets covariance matrix into three components by meeting the reflection symmetry. The advantage of the Freeman-Durden decomposition is that it is based on the physical mechanisms of radar backscattering, and its results are easy to correspond to typical scattering mechanisms. It is very practical for application.

We take the phase information into consideration in the dihedral and surface scattering mechanisms. The total covariance matrix $C$ is expressed as the sum of the three matrices accounting for the contributions of volume $C_{\mathrm{VOL}}$, surface $C_{\mathrm{ODD}}$, and dihedral $C_{\mathrm{DBL}}$, as proposed by Freeman and Durden:

$$
C=C_{\mathrm{VOL}}+C_{\mathrm{ODD}}+C_{\mathrm{DBL}}
$$

The first component of the Freeman-Durden decomposition consists of a first-order Bragg surface scatterer modeling slightly rough surface scattering in which the cross-polarized component is negligible. In this paper a phase difference between the $\mathrm{HH}$ and $\mathrm{VV}$ backscatter terms is included to model any propagation delay for $\mathrm{H}$ and $\mathrm{V}$ from radar to scatter and back $[28,29]$. The scattering $S$ matrix for a Bragg surface has the form

$$
\begin{gathered}
S=\left[\begin{array}{cc}
S_{h h} & 0 \\
0 & S_{v v}
\end{array}\right], \\
S_{h h}=R_{\mathrm{H}} e^{j \varphi_{h}}, \\
S_{v v}=R_{\mathrm{V}} e^{j \varphi_{v}}, \\
R_{H}=\frac{\cos \theta-\sqrt{\varepsilon_{r}-\sin ^{2} \theta}}{\cos \theta+\sqrt{\varepsilon_{r}-\sin ^{2} \theta}} \\
R_{\mathrm{V}}=\frac{\left(\varepsilon_{r}-1\right)\left\{\sin ^{2} \theta-\varepsilon_{r}\left(1+\sin ^{2} \theta\right)\right\}}{\left(\varepsilon_{r} \cos \theta+\sqrt{\varepsilon_{r}-\sin ^{2} \theta}\right)^{2}},
\end{gathered}
$$

where $\theta$ is the local incidence angle and $\varepsilon_{r}$ is the relative dielectric constant of the surface.

This scattering matrix yields a surface scattering covariance matrix $C_{\mathrm{ODD}}$ as

$$
C_{\mathrm{ODD}}=F_{S} \cdot\left[\begin{array}{ccc}
|\beta|^{2} & 0 & \beta \\
0 & 0 & 0 \\
\beta^{*} & 0 & 1
\end{array}\right],
$$

where $F_{S}$ corresponds to the contribution of the singlebounce scattering to the $\left|S_{\mathrm{VV}}\right|^{2}$ component, with $F_{S}=\left|R_{\mathrm{V}}\right|^{2}$ and $\beta=\left(R_{\mathrm{H}} / R_{\mathrm{V}}\right) e^{j \Delta_{\psi_{v h}}^{s}}$.

The double-bounce scattering component is modeled by scattering from a dihedral corner reflector, such as groundtree trunk backscatter, where the reflector surfaces can be made of different dielectric materials. The vertical trunk surface has reflection coefficients $R_{\mathrm{TH}}$ and $R_{\mathrm{TV}}$ for horizontal and vertical polarizations, respectively. The horizontal ground surface has Fresnel reflection coefficients $R_{\mathrm{GH}}$ and $R_{\mathrm{GV}}$. The model can be made more general by incorporating propagation factors $e^{2 j \gamma_{h}}$ and $e^{2 j \gamma_{\nu}}$, where the complex coefficients $\gamma_{h}$ and $\gamma_{v}$ represent any propagation attenuation and phase change effects. The covariance matrix for doublebounce scattering is therefore

$$
C_{\mathrm{DBL}}=F_{D} \cdot\left[\begin{array}{ccc}
|\alpha|^{2} & 0 & \alpha \\
0 & 0 & 0 \\
\alpha^{*} & 0 & 1
\end{array}\right],
$$

where $F_{D}$ corresponds to the contribution of the doublebounce scattering to the $\left|S_{\mathrm{VV}}\right|^{2}$ component, with

$$
F_{D}=\left|R_{\mathrm{TV}} R_{\mathrm{GV}}\right|^{2}, \quad \alpha=\frac{R_{\mathrm{TH}} R_{\mathrm{GH}}}{R_{\mathrm{TV}} R_{\mathrm{GV}}} e^{2 j\left(\gamma_{h}-\gamma_{v}\right)} .
$$

The volume scattering from a forest canopy is modeled as the contribution from a cloud of randomly oriented cylinderlike scatters. We then assume that the scatterers are randomly oriented about the radar look direction with an angle $\phi$ from the vertical polarization direction and the probability density function of the orientation angle is assumed to be uniform $(p(\phi)=1 / 2 \pi)$. The volume scattering averaged covariance matrix $C_{\mathrm{VOL}}$ is thus given by

$$
C_{\mathrm{VOL}}=\frac{F_{\mathrm{V}}}{8}\left[\begin{array}{lll}
3 & 0 & 1 \\
0 & 2 & 0 \\
1 & 0 & 3
\end{array}\right] \text {, }
$$

where $F_{\mathrm{V}}$ corresponds to the contribution of the volume scattering component.

For all of these backscatter components, it is assumed that the backscatter is reciprocal. It has also been shown that the like- and cross-polarized returns are uncorrelated. Taking into account the previous considerations, the main elements of the $C_{\text {int }}$ matrix can be decomposed as

$$
\begin{gathered}
C_{11}=F_{S}|\beta|^{2}+F_{D}|\alpha|^{2}+\frac{3 F_{\mathrm{V}}}{8}, \\
C_{13}=F_{S} \beta+F_{D} \alpha+\frac{F_{\mathrm{V}}}{8}, \\
C_{22}=\frac{2 F_{\mathrm{V}}}{8}, \\
C_{33}=F_{S}+F_{D}+\frac{3 F_{\mathrm{V}}}{8} .
\end{gathered}
$$

Now we can estimate the volume scatter contribution directly. The volume contribution can then be subtracted from $C_{11}, C_{13}$, and $C_{33}$ terms, leaving three equations and four unknowns. Based on van Zyl [30], we then interpret whether double-bounce or surface scatter is the dominant contribution in the residual, based on the sign of the real part of $S_{\mathrm{HH}} S_{\mathrm{VV}}^{*}$. If $\operatorname{Re}\left(S_{\mathrm{HH}} S_{\mathrm{VV}}^{*}\right)$ is positive, we deduce that surface scatter is dominant and fix $\alpha=-1$. If $\operatorname{Re}\left(S_{\mathrm{HH}} S_{\mathrm{VV}}^{*}\right)$ is negative, we know that double-bounce scatter is dominant and fix $\beta=1$. Then $F_{S}, F_{D}$ and $\beta$ or $\alpha$ can be estimated 


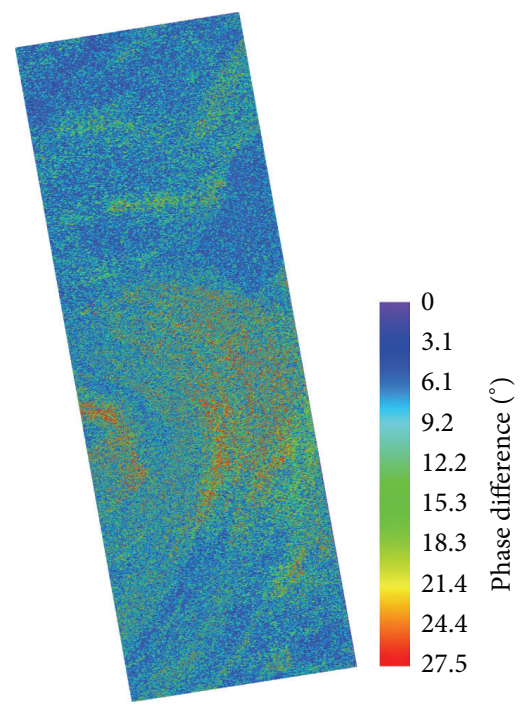

Figure 6: The distribution of the copolarized phase difference from the surface scattering contribution throughout the Lop Nur Lake area got from Freeman-Durden model-based decomposition method. In the lake area we can see significant changes in copolarized phase difference.

from the residual radar measurements. In most of our area the $\operatorname{Re}\left(S_{\mathrm{HH}} S_{\mathrm{VV}}^{*}\right)$ is positive, which indicates that the dominant contribution is surface scatter. We can therefore calculate out $|\beta|$ and $\Delta_{\psi_{v h}}^{s}$. Then, the copolarized phase difference of the surface scattering mechanism can be expressed as

$$
\phi_{\mathrm{HH}-\mathrm{VV}}=\Delta_{\psi_{v h}}^{s}
$$

\section{Results and Discussion}

To retrieve the brine layer depth, the copolarized phase difference from the surface scattering contribution in Lop Nur must be calculated first. Because of the special structure and chemistry of the Lop Nur surface and subsurface soil, there are several different scattering mechanisms. To extract and calculate the surface scattering mechanism and the corresponding copolarized phase difference, we used a physically based polarization decomposition method. In recent years, scattering model-based polarization decomposition methods have gained more attention, because we can establish a correspondence between its decomposition results and the specific scattering mechanism. It is also very easy to understand and apply.

We calculated the copolarized phase difference information of the Lop Nur Lake basin using the FreemanDurden decomposition as described in Section 2.2.2. The phase difference is due to the two-layer structure of the Lop Nur Lake basin. Figure 6 shows the distribution of the copolarized phase difference from the surface scattering contribution throughout the Lop Nur Lake area. We can see significant changes in the copolarized phase difference in the lake area, which is also distributed in a ring shape in the ancient lake in the Lop Nur region.

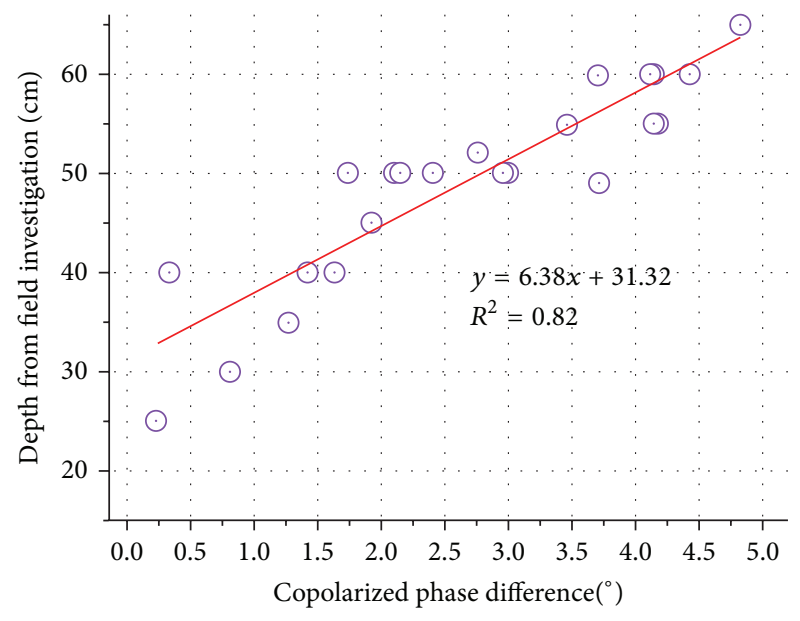

FIGURE 7: Comparison between $\phi_{\mathrm{HH}-\mathrm{VV}}$ from the surface scattering contribution using Freeman model-based decomposition and the measured depth results got from the field investigation. One scene of ALOS-PALSAR polarimetric data (L-band, quad-polarization, $23.9^{\circ}$ incidence angles for 6 May 2009) was used, with RMSE, $R^{2}$, and linear fitting formula shown. The solid line in diagram accounts for the linear fitting line.

Based on the research of Lasne et al., in areas that have a two-layer structure (a layer of wet soil covered by a dry sandy layer), there is a high correlation between the depth of the subsurface dielectric layer and the copolarized phase difference. Within a certain range of the depth distribution of the dry-upper layer, the copolarized phase difference increases with the depth of the subsurface wet layer. The Lop Nur Lake basin also has a two-layer scattering structure. There is a significant change in the dielectric properties of soil under the dry soil layer with a thickness of less than a meter, which indicates that it has a wet-dry change interface. To study the relationship between the copolarized phase difference due to the surface scattering and the depth of the brine layer in the Lop Nur region, we carried out a detailed field survey in 2013. A total of 32 sampling points were obtained from the lake region. The positions of the sampling points are marked out with red dots in Figure 1. Figure 7 shows the linear fit of the results between the copolarized phase difference and the brine layer depth at the same sampling points. One image of the ALOS-PALSAR polarimetric data (L-band, quad-polarization, $23.9^{\circ}$ incidence angle for May 6,2009 ) was used. We found that the copolarized phase difference has a good correlation with the subsurface brine layer depth, with a RMSE value and $R^{2}$ of $4.1 \mathrm{~cm}$ and 0.82 , respectively.

Based on the relationship established in Figure 7 and using the extracted copolarized phase difference from the model-based Freeman-Durden decomposition in the Lop Nur region, we calculated the brine layer depth for a line perpendicular to the stripes. The inversion results are shown in Figure 8. The ROIs (regions of interest) were selected perpendicular to the stripes and were evenly distributed along the center to the shore of the lake. We can see significant fluctuations of the subsurface brine layer depth along the 




FIgURE 8: The distribution of retrieved subsurface brine layer depth from the heart to the shore of the lake. To get the depth line 53 ROIs (regions of interest) were selected. The base map is HV polarization L-band ALOS image. Significant fluctuations of the subsurface brine layer depth along the center to the shore of the lake can be seen. Three anomaly areas of the depth profile are marked out by yellow boxes.

heart to the shore of the lake. In general, the subsurface brine layer depth increases from the center to the shore of the lake, which is in line with the general evolution of the lake retreat progress. However, Figure 8 shows three anomaly areas of the subsurface brine layer depth profile, indicated by the yellow boxes. If the water withdrawal process is continuous, then the extracted depth profile of the brine layer should have a continuous trend, and the anomaly areas in the figure will not appear.

After the drying-up process, the morphological traces of the Lop Nur Lake are the combined result of the chemical deposition of the upper surface and the invasion of the underground brine water deposition. First, it is needed to introduce the evolution of the surface salt crust. During the early lake retreat, the remaining water forms the prototype of the surface salt crust over a short time period. Then, the upper surface becomes dryer, and the brine water invades the upper layer by soil capillarity action crystallized in the nearsurface. Next, the underground brine rises to the subsurface and experiences crystallization. However, because of the pressure of the upper layer, the position of the brine water crystallization is continuously reducing. When it reaches a certain depth, the pressure of the upper layer and the force from the brine water crystallization will level off and will not have much impact on the upper and lower soil structure. This will increase the level of the horizontal pressure force and will ultimately form a dense layer, with an effect of holding the water below it, and finally the subsurface will have a distinct interface between wet and dry. Moreover, the formation of the ring textures of the lake should be analyzed, which are traces of its retreat. The bright stripes of the SAR image were formed during relatively dry periods. During this time very little water flowed into the lake and it retreated very quickly. The brine salt precipitation in the surface and underground has a joint effect on the formation of the bright stripes. The dark stripes formed during a sudden increase of the surface water in the lake, as it partially submerged the bright stripedregions that had formed before, namely, in the middle of a large lake retreat cycle; due to a temporary abrupt climate change, there will be several reciprocate cycles. Such sudden flood or climate events do not last long in general, after which there will be a rapid withdrawal process. Because of the short duration, it is assumed some of the salts up to the wet and dry interface will be lost. However, the dense interface between the wet and dry will not be affected. Therefore, the pressure from the layer above the wet and dry interface will be reduced, because of the force of the underground brine water, and the wet and dry interface in subsurface will be further uplifted. After this process a dark stripe will form, and its boundary between the bright stripes is clearly visible.

The satellite images of the Lop Nur area display light and dark, approximately concentric, ring structures. These ring stripes vary in width and are sometimes stacked. The "big ear," composed of the ring textures, is the most striking feature of Lop Nur in remote sensing images. Different interpretations have been provided for the ring-shaped stripes. Although the arguments differ, it is clear that each ring texture is the mark of a Lop Nur Lake border during a climate period. The depth of subsurface brine layer throughout the Lop Nur Lake area is shown in Figure 9. The depth map of the subsurface brine layer also has ring structures, which is consistent with common knowledge. 


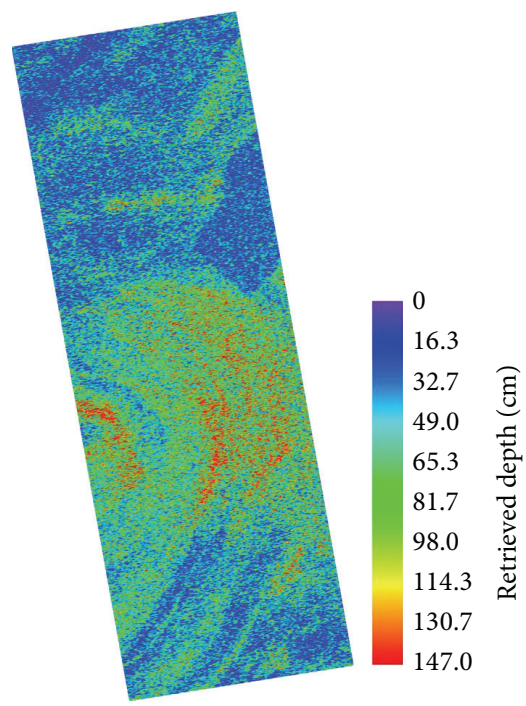

FIGURE 9: The distribution of the depth of brine layer throughout the Lop Nur lake area by phase inversion method. In the lake area we can see significant changes in depth. In this figure we used the mean filter with $11 \times 11$ windows size to highlight the differences.

However, using the inversion map, we found that the depth of the subsurface brine layer is different during each ring stripe (deeper in the northeast). This is contrary to the normal process of lakeshore retreat. In the general process of lakeshore retreat, the different parts of one ring stripe are formed during the same period and may have the same subsurface brine layer depth. This phenomenon may be due to the effects of wind stress, as proposed by Wang et al. [31], because there was a prevailing perennial northeasterly wind in the Lop Nur region. Particularly in the spring, the wind speed is up to $40 \mathrm{~m} / \mathrm{s}$. Thus, during the process of lake retreat, the northeast of Lop Nur was at times covered with water. Because of the strong evaporation in this part, the surface out of the water will have collected more crystallized salt. After the lake dried up, the expansion of the upper surface salinity became stronger and it was difficult for the underground brine water to rise and crystallize, which led to the increased depth of the subsurface wet and dry interface. The ring stripes in the southwest direction of the lake had not been out of the water and would experience the normal crystallization process. Therefore, the distribution of the depth of the subsurface brine layer is comparatively lower in the southwest direction of the lake. This phenomenon is particularly evident in Figure 9.

\section{Conclusions}

Based on field investigations and laboratory analysis, we studied the dielectric properties and structure of the soil layers in the Lop Nur lake region, where a subsurface wet and dry interface layer is thought to exist with different dielectric properties. We then simplified the structure of the soil in the Lop Nur Lake into a two-layer medium. The material composition of first layer is not uniform, with some pure salt and some saline mixed layers. The water content of first layer is very low. The second layer and the soil beneath it is very wet and contains a lot of salt, and the SAR signals cannot penetrate and continue to spread. Based on the theory proposed by Lasne et al. and the two-layer structure established above, we studied the relationship between the copolarized phase difference of the surface scattering and the dry medium thickness in the Lop Nur Lake region. The surface scattering copolarized phase difference is extracted using the model-based polarimetric decomposition method. By analyzing 25 field sampling points and the extracted surface scattering copolarized phase difference, we found a good linear correlation between the measured subsurface brine layer depth and the copolarized phase difference with an $R^{2}$ of 0.82 . This indicates that the inversion of the subsurface brine layer depth by copolarized phase difference is feasible.

On this basis, we calculated the copolarized phase difference and the subsurface brine layer depth of the entire lake area. By analyzing the distribution of the subsurface brine layer depth, we found that the dielectric layer depth has an overall trend with an increasing subsurface brine layer depth from the center to the shore of the lake, which is consistent with the known pattern of lake retreat. We found three anomaly areas on the profile of the subsurface brine layer depth, shown as a sudden deepening of the dielectric layer depth. This may be mainly due to a sudden injection of large amounts of flood water, which indicates a temporary regression of the drying-up cycle of the lake. The regression may also be caused by certain climate processes and will cause large structural changes to the soil layer in the Lop Nur Lake area. We have discussed the mechanism of this process in detail. Using the estimated depth map we found that the depth of the subsurface brine layer is different during each ring stripe (deeper in the northeast). This is contrary to the normal process of lakeshore retreat. Based on the hypothesis of the evolution of the surface salt crust and the wind stress factors, we are able to explain this phenomenon theoretically.

Remote sensing has advantages for studying geological phenomena on a large spatial scale. We have confirmed that the surface patterns and specific subsurface parameters, such as brine layer depth, are correlated with the process of paleoclimatic changes. Given the paleoclimatic significance of the Lop Nur Lake and based on the capability of SAR to detect structural and chemical parameters in subsurface layers, the reconstruction of historical evolution process of Lop Nur will be an interesting topic for future research.

\section{Conflict of Interests}

The authors declare that there is no conflict of interests.

\section{Acknowledgments}

The authors would like to express their sincere appreciation of the anonymous reviewers. This work was funded by the CAS Knowledge Innovation Program (KZCX2-EW-320), the National Natural Science Foundation of China (41431174, 
61471358, 41201346, U1303285, 41301394, and 41301464), the fund of the State Key Laboratory of Remote Sensing Science (Y1Y00201KZ), IRSA/CAS (Y3SG1900CX, Y1S01200CX), and Industry Application Projects (05-Y30B02-9001-13/15-03).

\section{References}

[1] X. C. Xia, Lop Nur in China, Science Press, Beijing, China, 2007.

[2] H. Y. Lü, X. C. Xia, J. Q. Liu et al., "A preliminary study of chronology for a newly-discovered ancient city and five archaeological sites in Lop Nor, China," Chinese Science Bulletin, vol. 55, no. 1, pp. 63-71, 2010.

[3] Y. Shao, H. Gong, Z. Gao, L. Liu, T. Zhang, and L. Li, "SAR data for subsurface saline lacustrine deposits detection and primary interpretation on the evolution of the vanished Lop Nur Lake," Canadian Journal of Remote Sensing, vol. 38, no. 3, pp. 267-280, 2012.

[4] B. Li, L. Ma, P. Jiang et al., "High precision topographic data on Lop Nor basin's Lake "great Ear" and the timing of its becoming a dry salt lake," Chinese Science Bulletin, vol. 53, no. 6, pp. 905914, 2008.

[5] F. Wang, C. Ma, X. Xia, Q. Cao, and Q. Zhu, "Environmental evolution in Lop Nur since late pleistocene andits response to the global changes," Quaternary Sciences, vol. 28, pp. 150-153, 2008.

[6] H. Z. Gong, SAR remote sensing research on subsurface targets detection and environmental evolution in Lop Nur palaeolacustrine basin [Ph.D. thesis], Institute of Remote Sensing Applications, Chinese Academy of Sciences, Beijing, China, 2010.

[7] H. Gong, Y. Shao, T. Zhang, L. Liu, and Z. Gao, "Scattering mechanisms for the 'ear' feature of lop nur lake basin," Remote Sensing, vol. 6, no. 5, pp. 4546-4562, 2014.

[8] Z. Gao, H. Gong, X. Zhou, Y. Shao, M. Yuan, and L. Wang, "Study on the polarimetric characteristics of the Lop Nur arid area using PolSAR data," Journal of Applied Remote Sensing, vol. 8, no. 1, Article ID 083681, 2014.

[9] J. F. McCauley, "Subsurface valleys and geoarcheology of the eastern Sahara revealed by shuttle radar," Science, vol. 218, no. 4576, pp. 1004-1020, 1982.

[10] R. G. Blom, R. E. Crippen, and C. Elachi, "Detection of subsurface features in SEASAT radar images of Means Valley, Mojave Desert, California," Geology, vol. 12, no. 6, pp. 346-349, 1984.

[11] G. G. Schaber, "SAR studies in the Yuma Desert, Arizona: sand penetration, geology, and the detection of military ordnance debris," Remote Sensing of Environment, vol. 67, no. 3, pp. 320347, 1999.

[12] G. G. Schaber and C. S. Breed, "The importance of SAR wavelength in penetrating blow sand in Northern Arizona," Remote Sensing of Environment, vol. 69, no. 2, pp. 87-104, 1999.

[13] G. G. Schaber, J. F. McCauley, C. S. Breed, and G. R. Olhoeft, "Shuttle imaging radar: physical controls on signal penetration and subsurface scattenng in the eastern sahara," IEEE Transactions on Geoscience and Remote Sensing, vol. 24, no. 4, pp. 603623,1986

[14] G. L. Berlin, M. A. Tarabzouni, A. H. Al-Naser, K. M. Sheikho, and R. W. Larson, "SIR-B subsurface imaging of a sand-buried landscape: Al Labbah Plateau, Saudi Arabia," IEEE Transactions on Geoscience and Remote Sensing, vol. GE-24, no. 4, pp. 595$602,1986$.
[15] M. G. Abdelsalam and R. J. Stern, "Mapping Precambrian structures in the Sahara desert with SIR-C/X-SAR radar: the Neoproterozoic Keraf suture, NE Sudan," Journal of Geophysical Research E: Planets, vol. 101, no. 10, pp. 23063-23076, 1996.

[16] A. E. Dabbagh, K. G. Al-Hinai, and M. A. Khan, "Detection of sand-covered geologic features in the Arabian Peninsula using SIR-C/X-SAR data," Remote Sensing of Environment, vol. 59, no. 2, pp. 375-382, 1997.

[17] G. G. Schaber, J. F. McCauley, and C. S. Breed, "The use of multifrequency and polarimetric SIR-C/X-SAR data in geologic studies of Bir Safsaf, Egypt," Remote Sensing of Environment, vol. 59, no. 2, pp. 337-363, 1997.

[18] Y. Lasne, P. Paillou, T. August-Bernex, G. Ruffié, and G. Grandjean, "A phase signature for detecting wet subsurface structures using polarimetric L-band SAR," IEEE Transactions on Geoscience and Remote Sensing, vol. 42, no. 8, pp. 1683-1694, 2004.

[19] P. Paillou, G. Grandjean, N. Baghdadi, E. Heggy, T. AugustBernex, and J. Achache, "Subsurface imaging in south-central Egypt using low-frequency radar: bir Safsaf revisited," IEEE Transactions on Geoscience and Remote Sensing, vol. 41, no. 7, pp. 1672-1684, 2003.

[20] G. Grandjean, P. Paillou, P. Dubois-Fernandez, T. AugustBernex, N. N. Baghdadi, and J. Achache, "Subsurface structures detection by combining L-band polarimetric SAR and GPR data: example of the pyla dune (France)," IEEE Transactions on Geoscience and Remote Sensing, vol. 39, no. 6, pp. 1245-1258, 2001.

[21] P. Paillou and T. August-Bernex, "Sub-surface imaging by combining airborne SAR and GPR: application to water detection in arid zones," in Proceedings of the International Geoscience and Remote Sensing Symposium (IGARRS '01), vol. 3, pp. 1384-1386, July 2001.

[22] P. Paillou, G. Grandjean, J.-M. Malézieux et al., "Performances of ground penetrating radars in arid volcanic regions: consequences for Mars subsurface exploration," Geophysical Research Letters, vol. 28, no. 5, pp. 911-914, 2001.

[23] Y. Lasne, P. Paillou, G. Ruffié, and M. Crapeau, "Effect of multiple scattering on the phase signature of wet subsurface structures: applications to polarimetric L- and C-band SAR," IEEE Transactions on Geoscience and Remote Sensing, vol. 43, no. 8, pp. 1716-1726, 2005.

[24] A. K. Fung, Z. Li, and K. S. Chen, "Backscattering from a randomly rough dielectric surface," IEEE Transactions on Geoscience and Remote Sensing, vol. 30, no. 2, pp. 356-369, 1992.

[25] A. K. Fung, Microwave Scattering and Emission Models and Their Applications, Artech House, Norwood, Mass, USA, 1994.

[26] S. R. Cloude and E. Pettier, "A review of target decomposition theorems in radar polarimetry," IEEE Transactions on Geoscience and Remote Sensing, vol. 34, no. 2, pp. 498-518, 1996.

[27] A. Freeman and S. L. Durden, "A three-component scattering model for polarimetric SAR data," IEEE Transactions on Geoscience and Remote Sensing, vol. 36, no. 3, pp. 963-973, 1998.

[28] A. Freeman, "Fitting a two-component scattering model to polarimetric SAR data from forests," IEEE Transactions on Geoscience and Remote Sensing, vol. 45, no. 8, pp. 2583-2592, 2007.

[29] J. D. Ballester-Berman and J. M. Lopez-Sanchez, "Applying the Freeman-Durden decomposition concept to polarimetric SAR interferometry," IEEE Transactions on Geoscience and Remote Sensing, vol. 48, no. 1, pp. 466-479, 2010. 
[30] J. J. van Zyl, "Unsupervised classification of scattering behavior using radar polarimetry data," IEEE Transactions on Geoscience and Remote Sensing, vol. 27, no. 1, pp. 36-45, 1989.

[31] L. Wang, H. Gong, Y. Shao, and B. Li, "Analysis of elevation discrepancies along the Lop Nur ear-shaped stripes observed using GLAS and DGPS data," International Journal of Remote Sensing, vol. 35, no. 4, pp. 1466-1480, 2014. 

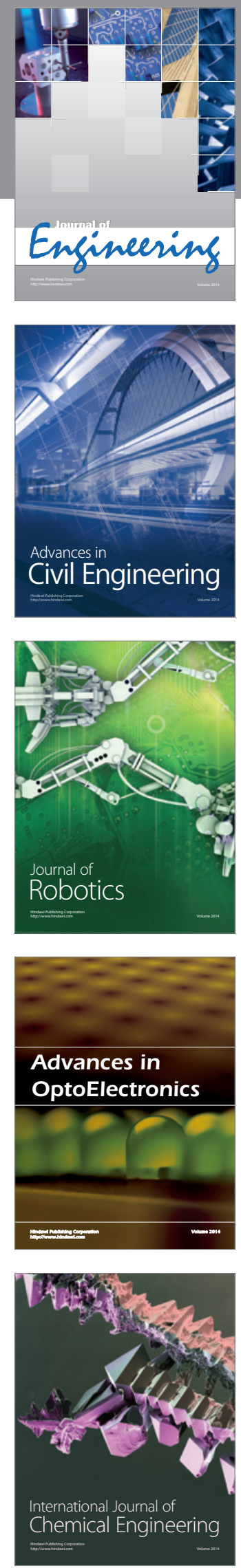



The Scientific World Journal
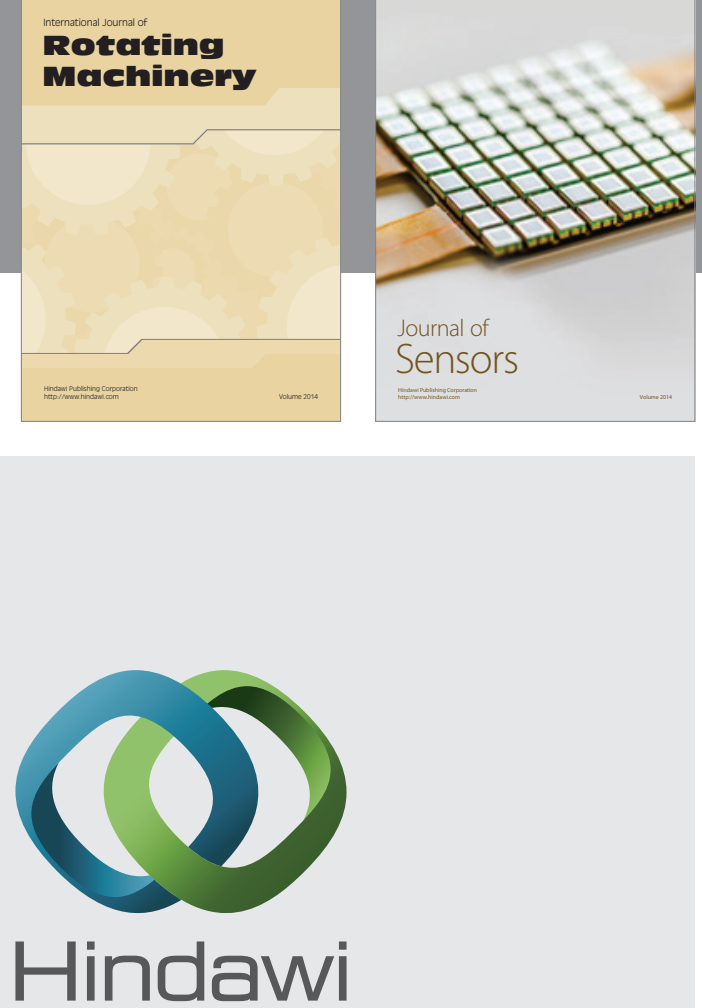

Submit your manuscripts at http://www.hindawi.com
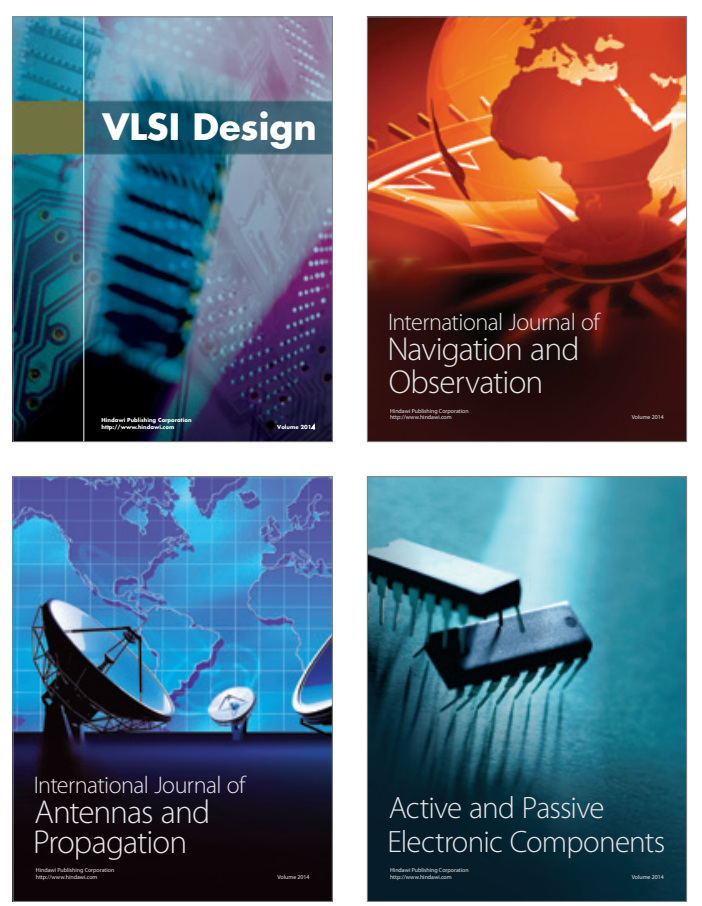
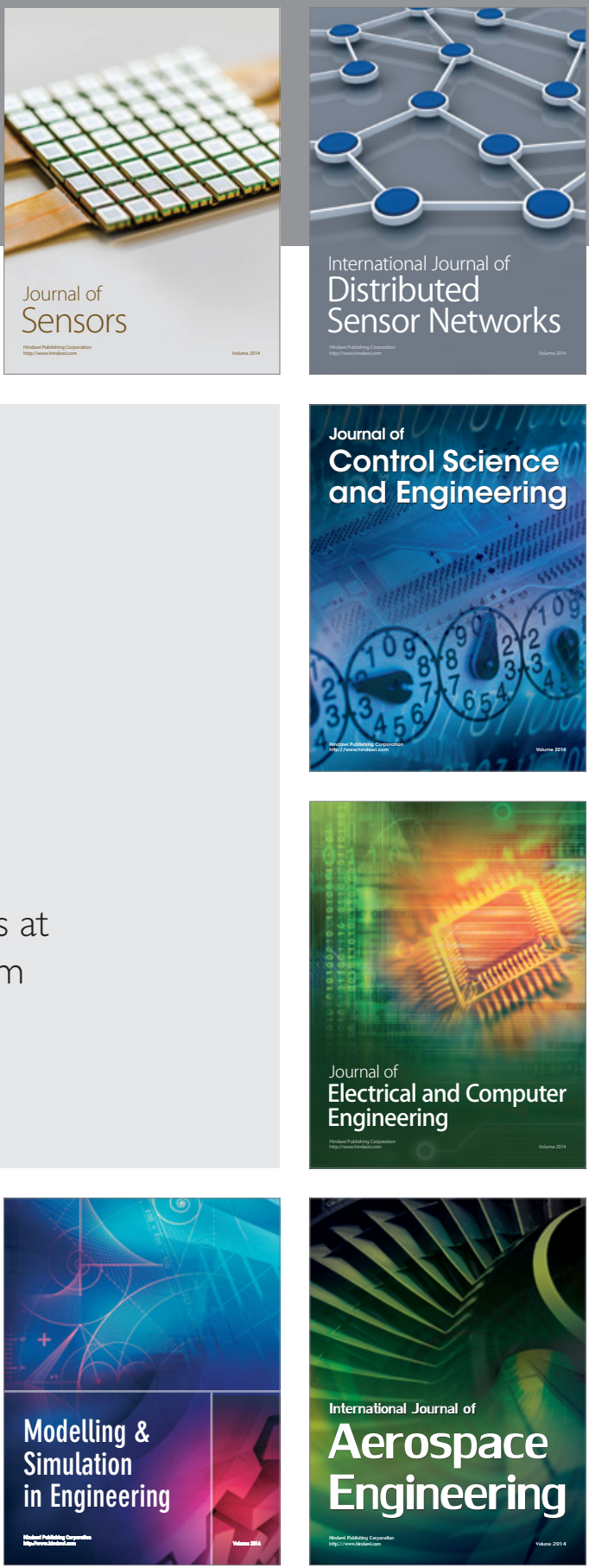

Journal of

Control Science

and Engineering
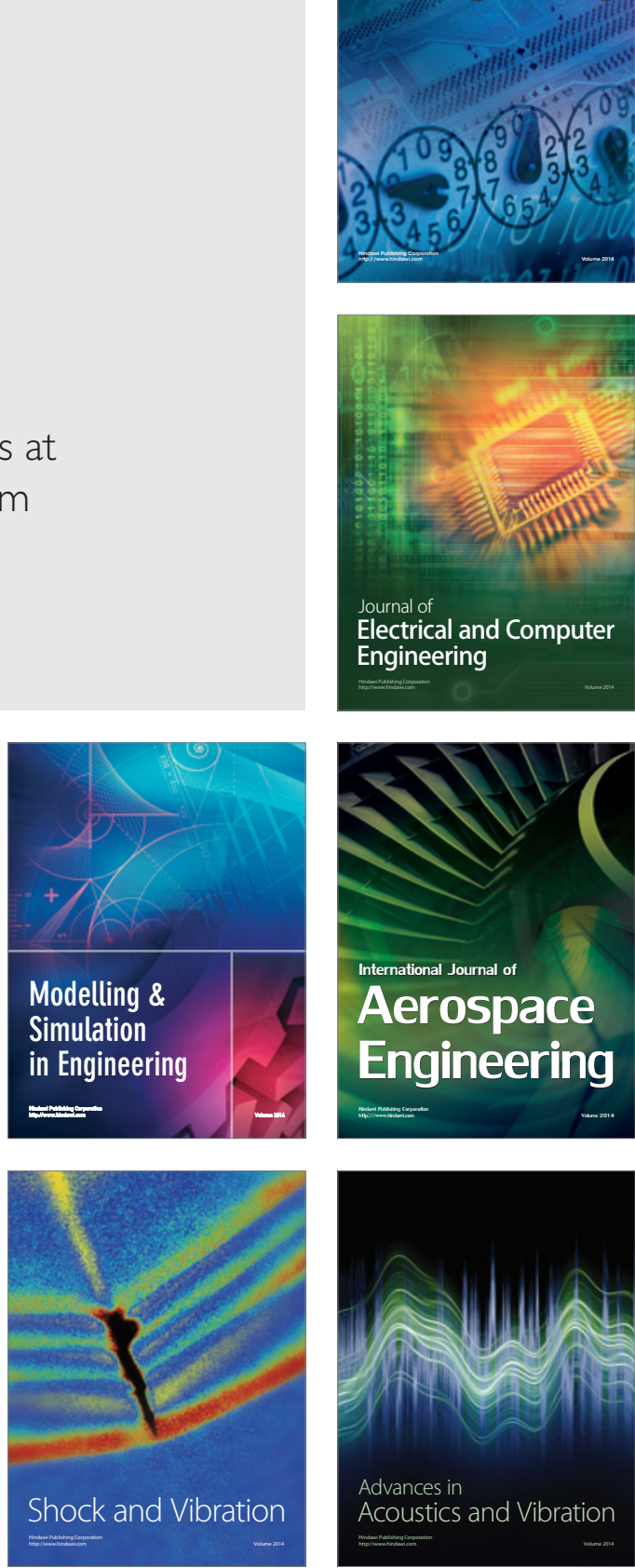